Ч. М.-Х. Тензин, Е. О. Мальшева. Туристская дестинация Тувы: основные факторы развития и перспективы

УДК 316.34

DOI: 10.18101/1994-0866-2019-4-57-63

\title{
ТУРИСТСКАЯ ДЕСТИНАЦИЯ ТУВЫ: ОСНОВНЫЕ ФАКТОРЫ РАЗВИТИЯ И ПЕРСПЕКТИВЫ
}

\section{(c) Тензин Чодураа Мочак-Хаевна}

кандидат социологических наук, ведущий научный сотрудник, Тувинский институт гуманитарных и прикладных социально-экономических исследований Россия, 667000, г. Кызыл, ул. Кочетова, 4

E-mail: tenzinchoduraa@gmail.com

\section{(C) Малышева Евгения Олеговна}

аспирант,

Российский государственный педагогический университет им. А. И. Герцена

Россия, 667000, г. Кызыл, ул. Красных Партизан, 18

E-mail: evgena.malysheva@gmail.com

Туристская дестинация - это место, территория, социально-географическое пространство, туристическая инфраструктура, т. е. не только материальная сторона, внутри дестинации заложен эффект аттракций, притяжений, познаний, культурного преобразования личности от туристических услуг и сервиса на месте пребывания. Это сложный феномен, в существовании которого задействованы все отрасли экономики, все субъекты управления, множество социальных групп, чьи интеракции сплетены разными символами и действиями. Тува как туристская дестинация сформировалась исторически в сплетении разных цивилизаций и культур, которые сохранились до настоящего времени. Тува - это колыбель скифской цивилизации, разнообразие тюркской, уйгурской, кыргызской, монгольской, китайской и русской культур, в природном ландшафте сконцентрированы разные природно-климатических зоны, начиная от таежных до степных территорий. Это единство разнообразия в экологическом и культурном аспектах создает повышенную аттрактивность и притягательность социального пространства, формируя положительный бренд туристической территории. На основе этого важным является создание эффективной модели управления туристской дестинации во взаимодействии всех социальных групп, которые также будут влиять на имидж республики.

Ключевые слова: туристская дестинация; аттракции; интеракции; бренд; препятствия в развитии туристской дестинации.

\section{Для цитирования}

Тензин Ч. М.-Х., Малышева Е. О. Туристская дестинация Тувы: основные факторы развития и перспективы // Вестник Бурятского государственного университета. Философия. 2019. Вып. 4. С. 57-63.

Научные исследования туристской дестинации с позиции гуманитарных наук становятся востребованными в силу практического интереса к туризму, имеющее больше философское, социокультурное, психологическое значение в процессе познания местности и людей, проживающих на территории посещения.

Философское значение туристской дестинации основывается на мировосприятии местности, в первую очередь проживающего в нем народа и их отношения к 
месту своего обитания. Философия жизни тувинцев тесно связана с кочевым образом жизни, особым культурным поведением, высокой адаптивностью к местам кочевки. Кочевники-тувинцы бережно относились к местности, ценили окружающую среду и верили, что земля - это мать, а небо - отец. Небо (или Кок-Дээр) оплодотворяло землю, и от неба, его тепла и света зависели плодородие и благополучие. Небу поклонялись как пространству небожителей и богов, а Земле как источнику богатства и урожая. Особо почитали природные силы, от которых зависели условия жизни, кочевки и переезды. Человек в структуре мироздания представлял промежуточное звено, который не нарушал баланс, а наоборот - создавал умиротворение природных начал. Небесный (высший мир), земной (средний мир), подземный (низший мир) уровни мироздания представляют круговорот рождений существ в бытие. В зависимости от духовных накоплений существо получает то или иное рождение. Человеческое рождение считается наиболее благоприятным. Однако оно уступало силам природы, поэтому человек, вступая в контакт с живой природой, всегда брал разрешение, своего рода «согласие» для существования, преодолевая суровые климатические и природные условия. Кочевники перед охотой совершали обряды позволения, восхваляли природу — мать и небо-отца, старались никогда не загрязнять местности.

Природа - живое, одухотворенное, могущественное явление, и тувинцы издревле верили, что важно не нарушать экологию, ее баланс и гармонию. Чуткое соблюдение законов природы благоприятно влияло на окружающую среду, прежде всего на самого человека. Чем ближе человек был к природе, тем лучше он ориентировался в среде, распознавал природно-климатические изменения, благоприятно адаптировался. Человек с космологическим мировоззрением точно прогнозировал и предсказывал природные явления. Сливаясь с природой, кочевник знал все взаимосвязи природы, поэтому он обладал редким природным даром, что без труда воспроизводил звуки природы через горловое пение и музыку.

Космическое кочевое мировосприятие объединяло гео-, эко-, био-, психосистемы в одну Вселенную. Одаренные люди с развитыми способностями переключаются из одной системы в другое, могут видеть различные существа из разных миров. Наиболее сильные существа обитали в высшем мире, к которым люди и поклонялись, обращаясь за помощью для устранения катаклизмов, голода, болезней и войн. Тувинцы до сих пор особо почитают духов местностей - земли, гор, тайги и воды.

Социокультурное значение туристской дестинации выражается в разнообразии культур, традиций и обычаев народов, живущих в местности туризма и отдыха. Чем богаче дестинация, тем известен ее бренд, притягивающий туристический поток, приносящий прибыль для региона. Туристическая отрасль связана со всеми областями экономики и имеет мультипликативное воздействие на имидж и аттракции туристических мест. Психологическое значение туристской дестинации основывается на изучении аттракций, имидже и уровне посещаемости того места, куда человек направляется. Местность может притягивать или отталкивать людей, а также вызывать определенные чувства, воспоминания и переживания.

В России одним их важных направлений в развитии туризма являются трансграничные и приграничные территории, находящиеся на границе с Китаем и Монголией. Республика Тыва является локальной территорией, граничит с Монголией, 
Ч. М.-Х. Тензин, Е. О. Мальшева. Туристская дестинация Тувы: основные факторы развития и перспективы

находится в южной части Восточной Сибири. Исторически Тува представляет особый интерес для российского и китайского бизнеса, т. к. в ней сосредоточены богатства минерально-сырьевой базы, разнообразие водных ресурсов, редкие растения и животные, уникальные памятники культуры и искусства, а также все виды туризма.

Туристская дестинация Тувы является по характеру достаточно неосвоенной территорией в сфере использования ее ресурсного потенциала, как туристического, так социального, культурного и экологического. В настоящее время разработаны проекты промышленного освоения территории Тувы, в виду этого создаются программы развития транспортной, социальной инфраструктуры, связи и коммуникации, туризма.

Региональная экономика не учитывает в полном масштабе особенности разнообразия флоры и фауны, ландшафт территории, сохранность культурных традиций народов, проживающих в данной территории, представляя огромный туристический потенциал. Тува как особая туристская дестинация, представляя богатый регион туристических возможностей, не имеет логической разработанной программы в сфере регионального туризма и модели управления. Отсутствуют управленческие эффективные программы развития регионального туризма, не создаются благоприятные условия для совершенствования массового внутреннего туризма, отсутствуют единые механизмы управления, начиная с муниципальных органов власти и заканчивая отдельными акторами туристической деятельности. Изза отсутствия региональной концепции развития туризма не вырабатываются единые действия, эффективные взаимодействия для улучшения положительного имиджа туристской дестинации в регионе. В региональном управлении планомерно не учитывают финансовые затраты на улучшение и создание благоприятной туристической среды. Социальные факторы напрямую влияют на систематическое получение прибыли от туристической деятельности. Если социальные факторы имеют отрицательные показатели, следовательно, туристская дестинация будет иметь эффект отторжения и разрушения имиджа региона.

Тува представляет не только регион в российской действительности, но и социальное пространство, в котором взаимодействуют группы, институции, которые либо объединяются общими интересами и свойствами, либо, соприкасаясь между собой, удаляются друг от друга. П. Бурдье сравнивает социальное пространство с «полем» и объясняет, что это ситуация социального взаимодействия в границах определенного пространственно-временного континуума [1].

Тува - это потенциальный туристический регион, имеющий огромные возможности для развития внутреннего и международного туризма, в особенности экологического, этнографического, культурного (религиозного), исторического, экстремального, медицинского и других видов туризма. Потенциал Тувы основывается на том, что помимо природного богатства в ней сосредоточено множество древних исторических памятников, разнообразие культур народов, проживающих на данной территории.

Приоритетным направлением в улучшении социально-экономической сферы считается развитие социального сектора, которое предполагает решение проблемы безработицы, поддержку социально уязвимых групп населения (инвалиды, пенсионеры, сироты и другие), строительство социальных объектов (детские сады, 
школы и другие учреждения), установление правопорядка и борьбу с преступностью [3, с. 45]. Главным фактором для развития тувинской туристкой дестинации является развитие и совершенствование социальной сферы. Это не только приоритетное направление в социально-экономическом развитии региона, но и высокий уровень жизни населения, социальное самочувствие населения, его духовное богатство, культурная, политическая, финансовая, правовая грамотность. Первый уровень актуальных направлений в социально-экономическом развитии Тувы связан с решением проблемы безработицы и развитием сельского хозяйства. Второй уровень - это строительство социальных объектов, социальная поддержка населения, привлечение инвестиций в экономику республики. Третий уровень - правопорядок, борьба с преступностью, развитие туризма, национальной культуры и развитие малого и среднего бизнеса [2, с. 46].

Важными факторами в развитии туристской дестинации являются поддержка социальной сферы, малого предпринимательства, организаторов туризма; привлечение инвестиций в сельское хозяйство и производство. Вышеперечисленные факторы влияют на благополучие туристской дестинации, достижение ее высокого потенциала. Первичные факторы улучшения туристской дестинации Тувы - это решение проблемы занятости населения, развитие высокой культуры и активность граждан.

В 2017 г. совместно с Информационным центром туризма Республики Тыва был проведен опрос городского населения, в котором приняли участие 551 человек, в основном молодежь. Результаты опроса показывают, что в Туве развит внутренний туризм (в Туве отдыхают $49,5 \%$, а в России - $29,4 \%$ ), чей туристический выбор основывается на ценовой доступности $(42,4 \%)$, безопасности отдыха $(32,1 \%)$, бренда туристичесского места $(25,9 \%)$ (табл. 1$)$.

Таблица 1

Вопрос «Какие страны Вы чаще всего посещаете?»:

\begin{tabular}{|c|c|c|}
\hline & Респонденты & $\%$ \\
\hline Ценовая доступность & 239 & 42,4 \\
\hline Доступность средств транспортного сообщения & 137 & 24,3 \\
\hline $\begin{array}{l}\text { Популярность региона как туристического бренда и его } \\
\text { известные достопримечательности }\end{array}$ & 146 & 25,9 \\
\hline Хороший уровень сервиса & 123 & 21,8 \\
\hline Отзывы туристов & 92 & 16,3 \\
\hline Безопасность отдыха & 181 & 32,1 \\
\hline $\begin{array}{l}\text { Доброжелательное отношение местного населения к тури- } \\
\text { стам }\end{array}$ & 129 & 22,9 \\
\hline Реклама & 31 & 5,5 \\
\hline Привычки & 77 & 13,7 \\
\hline Другое & 17 & 3,0 \\
\hline
\end{tabular}

Туристическая инфраструктура в Туве имеет удовлетворительный характер (минимальный показатель - 31,1\% и максимальный - 42\%). Положительную 
Ч. М.-Х. Тензин, Е. О. Мальшева. Туристская дестинация Тувы: основные факторы развития и перспективы

оценку получили скульптурный комплекс «Центр Азии» (32,7\%), сувенирная деятельность (16,4\%), спортивные сооружения $(12,2 \%)$, общественное питание $(10,1 \%)$. В критичном положении находятся дороги $(21,3 \%)$, безопасность $(12,8 \%)$, турфирмы $(11,8 \%)$.

Скульптурный комплекс «Центр Азии», автором которого является известный бурятский скульптор Д. Намдаков, был построен накануне празднования 100летия протектората над Тувой в 2014 г. [2]. Обелиск «Центр Азии» сменил образ, связанный с мотивами скифского золота, хранящегося в Национальном музее Республики Тыва. Как видно из результатов опроса, этот комплекс занял первое место по оцениванию туристической инфраструктуры. Большинство респондентов в целом удовлетворительно оценивают туристическую индустрию в Туве $(52,3 \%)$ и оптимистично надеются на лучшие перемены в изменении туриндустрии $(72,6 \%)$.

Главными факторами, препятствующими развитию туризма в Туве, являются слабая региональная программа развития туризма $(37,8 \%)$, сложность транспортной доставки и высокая стоимость проезда $(27,7 \%)$, нестабильность социальноэкономической ситуации (27,5\%), отсутствие хорошей инфраструктуры (условия проживания, транспортных средств, необходимого сервиса) (21,5\%) (табл. 2).

Таблица 2

Вопрос «Какие факторы сейчас препятствуют развитию туризма в Туве?»:

\begin{tabular}{|c|c|c|}
\hline & Респонденты & $\%$ \\
\hline $\begin{array}{l}\text { Слабая региональная программа развития ту- } \\
\text { ризма }\end{array}$ & 213 & 37,8 \\
\hline $\begin{array}{l}\text { Нестабильность социально-экономической си- } \\
\text { туации }\end{array}$ & 155 & 27,5 \\
\hline $\begin{array}{l}\text { Сложность транспортной доставки и высокая } \\
\text { стоимость проезда }\end{array}$ & 156 & 27,7 \\
\hline $\begin{array}{l}\text { Отсутствие инфраструктуры (условий прожи- } \\
\text { вания, транспортных средств, необходимого } \\
\text { сервиса) }\end{array}$ & 121 & 21,5 \\
\hline $\begin{array}{l}\text { Потенциальные посетители не знают о туристи- } \\
\text { ческих возможностях региона }\end{array}$ & 114 & 20,2 \\
\hline Предпринимательские барьеры (налоги) в тури- & 50 & 8,9 \\
\hline $\begin{array}{l}\text { стическом бизнесе, отсутствие поддержки пра- } \\
\text { вительства, властей для агентов турбизнеса }\end{array}$ & 111 & 19,7 \\
\hline $\begin{array}{l}\text { Низкая платежеспособность населения для от- } \\
\text { дыха и рекреации }\end{array}$ & 109 & 19,3 \\
\hline $\begin{array}{l}\text { Недостаточная квалификация агентов в турдея- } \\
\text { тельности }\end{array}$ & 59 & 10,5 \\
\hline $\begin{array}{l}\text { Отсутствие туристических программ и предло- } \\
\text { жений туров }\end{array}$ & 54 & 9,6 \\
\hline Низкий уровень сервиса туристических услуг & 111 & 19,7 \\
\hline $\begin{array}{l}\text { Недостаточная взаимосвязь агентов в турбиз- } \\
\text { несе с другими фирмами, муниципальными и } \\
\text { государственными органами }\end{array}$ & 85 & 15,1 \\
\hline
\end{tabular}




\begin{tabular}{|l|c|c|}
\hline $\begin{array}{l}\text { Отток квалифицированных кадров за преде- } \\
\text { лами Тувы }\end{array}$ & 15 & 2,7 \\
\hline Другое & 2 & 1,4 \\
\hline
\end{tabular}

Туризм в Туве прямо пропорционально влияет на создание новых рабочих мест (42,6\%), повышает культуру местных жителей (40,6\%), улучшает взаимоотношения между народами (36,2\%) 44,8\% респондентов прогнозирует, что туризм в Туве будет развиваться и приносить доход населению.

Многие жители не заинтересованы в улучшении туристического имиджа Тувы (36,2\%), но находятся те, кто борется с алкогольным движением (20,9\%), беседует с молодежью о здоровом образе жизни $(14,9 \%)$ и обучает людей культурному поведению, стилю жизни (11,3\%).

Решение проблем развития инфраструктуры (48\%), подготовки квалифицированных турагентов и гидов, а также создание этнографического комплекса $(39,2 \%)$ будут способствовать развитию экономики Тувы, поэтому местному турбизнесу необходимо ориентироваться на российский $(21,2 \%)$ и азиатский (Монголия, Китай и другие страны) турпоток (12,3\%).

В туристской дестинации Тувы важно совершенствовать управление в социальной, политической, экономической, национальной международной сферах. В целом управленческая модель развития туристской дестинации в Туве не получает целостного развития из-за отсутствия логистического центра туризма в регионе, в котором бы изучались интересы субъектов туристической деятельности, туристов и местных жителей. Эффективное управление туристской дестинацией предполагает достижение благополучного развития всех сфер общества, формирование социального эффекта от туристической деятельности для увеличения числа занятых в туристических объектах, а также всех видов услуг туризма. Эффективная модель управления основывается на гармоничном балансе экономической выгоды, в котором должны быть заинтересованы не только государственные структуры, но и бизнес-структуры, также важно участие местного населения. Именно жители создают безопасность, тренд и имидж территории, от их отношения к туризму и правильного использования туристических ресурсов зависит сохранение экологической чистоты, что привлекает туристов в Туву. Туристская дестинация Тувы, включая экологический, культурный, этнографический, религиозный виды туризма, должна совершенствоваться, а модель управления туристской дестинацией строиться на фильтрации туристов из трансграничных территорий. Закрытая территория Тувы, слаборазвитая инфраструктура в принципе создают искусственные барьеры для посещаемости туристов, но при массовом въезде иностранных туристов необходимо совершенствовать базу реестров туристов, контролировать их действия на территории для сохранения экологического, культурного и духовного пространства туристской дестинации Тувы.

В заключении отметим, что туристская дестинация Тувы имеет естественное образование положительных аттракций и вызывает большой интерес у туристов, несмотря на негативный концепт о Туве. Данные стереотипы разрушаются после посещения Тувы, меняются мотивы и потребности у туристов. В целом преобладает положительная тенденция брендирования территории. Для повышения эф- 
фективного управления туристской дестинацией необходимо использовать модель управления, которая будет объединять всех субъектов туристической деятельности для достижения единой цели — развития региона.

\section{Литература}

1. Бурдье П. Социология социального пространства / пер. с франц.; отв. ред. пер. Н. А. Шматко. М.: Изд-во Ин-та экспериментальной социологии; СПб.: Алетейя, 2007. $146 \mathrm{c}$.

2. Тензин Ч. М.-Х. Стратегические приоритетные направления социально-экономического развития региона: место туризма в Туве // Развитие туризма в Республике Тыва: материалы регион. конф. Кызыл, 2016. С. 45.

\section{TOURIST DESTINATION OF TUVA:}

\section{KEY DEVELOPMENT FACTORS AND PROSPECTS}

\section{Choduraa M.-Kh. Tenzin}

Cand. Sci. (Sociol.), Leading Researcher,

Tuva Institute of Humanitarian and Applied Social and Economic Research

4 Kochetova St., Kyzyl 667000, Russia

Email: tenzinchoduraa@gmail.com

\section{Evgeniya O. Malysheva}

Research Assistant,

Herzen Russian State Pedagogical University

18 Krasnykh Partisan, Kyzyl 667000, Russia

E-mail: evgena.malysheva@gmail.com

Tourist destination is a place, territory, socio-geographical space, tourist infrastructure, i. e. it has not only the material side, but also the effect of attractions, knowledge, cultural transformation of a person from tourist services that laid inside the destination. This is a complex phenomenon, and all sectors of the economy, all subjects of government, many social groups and their interactions with different symbols and actions are involved in its existence. Tuva developed as a tourist destination in the borderland of different civilizations and cultures that have survived to the present. Tuva is not only the cradle of Scythian civilization, but also the diversity of Turkic, Uyghur, Kyrgyz, Mongolian, Chinese and Russian cultures, it has different natural climatic zones, ranging from taiga to steppe territories. The unity of environmental and cultural diversity creates increased attractiveness of the social space, and a positive brand of the tourist territory. In view of this it is important to create an effective model of managing tourist destination in the interaction of all social groups affecting the image of the republic.

Keywords: tourist destination; attractions; interactions; brand; obstacles in tourist destination development. 